\title{
Challenges in Sustaining the Malay Traditional Kuih among Youth
}

\author{
Humairah Hamzah, Muhammad Shahrim Ab. Karim, Mohiddin Othman, Azimi Hamzah, and Nur \\ Hafizah Muhammad
}

\begin{abstract}
The purpose of the article is to disclose the challenges in sustaining the Malay traditional kuih with differing levels of acceptance among youth in East Coast Peninsular Malaysia. Malay kuih also known as Malay dessert that referring to a product which uses specific raw ingredients; methods; processes; techniques; materials and utensils; and the recipes have been passed down from one generation to other generations. It is part of Malaysian culture, identity and heritage that should be sustained by all generations especially youth. Throughout observation and interviews with youth, age of 18 to 25 years old who are completed their secondary school and basically come from different family backgrounds, the trend of buying pattern among youth towards Malay traditional kuih were influenced by the family, friends and occasions. Six main themes that have been identified are including family, value, knowledge, motivation, way of life and pecuniary. Although all themes were emphasized by youth during the interviews, a closer look revealed that the themes evaluated quite differently based on their age and background. The exhibited divergences are found to be underpinned by different way of life dispositions, which are extremely important and affecting in shaping and influencing values amongst the youth. The results are promising meaningful understanding of the challenges to sustain the Malay traditional kuih among youth, which are reinforced by its complex culture diversities and globalization.
\end{abstract} food.

Index Terms-Family, Malay kuih, motivation, traditional

\section{INTRODUCTION}

Nowadays everyone talks about, traditional, authenticity, heritage, sustaining food and it seem like everybody is concerned about this issue. This article will identify and reveal the challenges to sustain the Malay traditional kuih among youth in the city of Kota Bahru, Kuala Terengganu and Kuantan in the East Cost of Malaysia.

Manuscript received January 5, 2014; revised March 7, 2014. This work was supported in part by the Department of Food Service and Management, Faculty of Food Science and Technology, Universiti Putra Malaysia (UPM).

H. Hamzah is with the Department of Food Service and Management, Faculty of Food Science and Technology, Universiti Putra Malaysia, 43400 Serdang, Selangor, Malaysia (e-mail: humairahhamzah@gmail.com).

M. S. Ab Karim and M. Othman are with the Universiti Putra Malaysia, 43400 Serdang, Selangor, Malaysia (e-mail: shahrim@upm.edu.my, mohiddin@upm.edu.my).

A. Hamzah is with the Institute of Social Science Research (IPSAS), Putra-Info Port, Universiti Putra Malaysia, 43400 Serdang, Selangor, Malaysia.

N. H. Muhammad is with the Universiti Malaysia Kelantan, 16100 Pengkalan Chepa, Kelantan, Malaysia (e-mail: nurhafizahm@umk.edu.my).
Traditional foods are part of culture, identity, and heritage for every part of countries all around the world. The European declared that traditional are related to the food and the traditional means usage in the community market for certain period of time showing the transmission between generations to other generations. According to Prof. Datuk Zuraina Majid, Malaysia Heritage Commissioner [1] p. 24 heritage food is categories into two, first categories refers to common foods which are part of lives but people are unaware of their heritage value and second consists of foods that represent our culture but slowly dying out like halwa and some of the kuih. Traditional food is referred to foods that are differentiated through particular qualitative aspects with special cultural identity [2].

One of the main challenges of the twenty-first century is to establish a sustainable society, meaning development that meets the needs of the present without compromising the ability of future generations to meet their own needs [3] p. 368. It is crucial that these traditional foods are preserved for future generations [4]. Also important is that a sustainable society should be built on the three pillars of ecological, social and economic sustainability. This includes a society where nature and heritage are maintained through people making various choices based on everyday and local knowledge and traditions for the benefit of their own development and that of future generations.

Diversity is the attractiveness of Malay traditional food and this is evident in all kinds of kuih or known as cakes and snacks are handed down from one generation to the next generation among the Malay community. Traditional kuih are differentiated through particular qualitative aspects through discovery something hidden and have a specific cultural identity. It is an expression of culture, history and lifestyles of local people in Malaysia. And also related to the local ingredients, methods, equipments and utensils used which highly engage with the knowledge and skills of local people.

Research on youth value and culture in Malaysia has shown that cultural patterns and values among youth are changing. Most people believe this is the result of variety of factors, including the primary role of global culture that is inundating youth through a variety of forms of mass media. How else can one explain the emulation by young Malay in terms of the appearance, behaviors and eating habits of their western counterparts, despite never having come in to contact with them? Globalizations give impact on the challenges in dissolving of local cultures - possibilities to lose our traditional Malaysian food heritage. The youth not only represents as a mediator of culture through sustaining our heritage but also as the agent of marketing and branding that 
is necessary in creating sustainable small-scale business production on local traditional kuih and, therefore, as local cultural sustainability.

Youth are an important asset to preserve the heritage food from rapid globalization. Global consumerism can cause divides in young people by creating new hybrid of cultural forms whose meanings are different from local and national values. Youth as defined by the United Nations refer to post-adolescent and pre-adult groups between the ages of 15 and 24 [5]. The National Youth Development Policy of Malaysia defines youth as people aged between 15 and 40 years. It stipulates further that the main focus of youth development programs and activities in the country are for those aged between 18 to 25 years.

In addition to traditional Malay value, kuih also has a significant societal, historical and religious role. Malaysia food has been associated with cultures and ethnic groups for centuries [6]. Knowledge of traditional kuih is often passed from generation to generation through oral traditions. The role of traditional kuih in cultural practices and religious beliefs is complex and varies among individuals and communities. Academic research in developing countries has, to a certain extent, ignored the manner in which culture and value systems influence food consumption and therefore the understanding remains unclear. Nevertheless, it has been determined by preliminary 'studies that the motivations and determinants of consumer attitudes and consumption behavior are the core of personal values [7].

Although globalization makes the world more homogenous people still need to be aware and sensitive to the cultural differences [8]. Human behavior occurs within a cultural context and the evidence shows that there is lacking research on youth based values or attitudes to the Malay traditional kuih. To address this issue, the aim of this article is to identify and to reveal the challenges in sustaining the Malay traditional kuih from youth's perspectives in East Cost Malaysia using qualitative approaches.

\section{Methodology}

This article is conducted with the aims to evaluate the awareness among youths in sustaining the Malay traditional kuih among youth in East Coast Malaysia and the states are Kelantan, Terengganu and Pahang. Participant and non-participant observations were conducted throughout many of restaurants, bazaars Ramadan, cafeterias and food stalls, while a series of interviews were carried out with local youth, all of whom provided their memories and reflections on Malay traditional 'kuih'. In all, 12 participants, of mixed gender and socio-economic background, covering age-range of 18 to 25 years, were interviewed in their own homes. Data were collected during 60 to 90-minutes semi structured interviews. The interview schedule, containing both open and closed-ended questions, covered a wide range of questions regarding demographic, socio-economy, family background, education, participation in informal activities and knowledge on traditional Malay kuih. Data for the qualitative analysis are derived from semi structured interviews, information from key informants, and field observation. There a few unstructured questions used to allow respondents to describe their experiences and knowledge on the subject using their own words.

This combination of observation, archival and narrative data was analyzed with a view to identifying the ways in which information come to be embedded within various forms from youth and too peeled out the challenges in sustaining the traditional Malay kuih. The main objective is to identify and to reveal what are the challenges in sustaining traditional Malay kuih amongst the youth in the capital city of Kelantan, Terengganu and Pahang. These States are very popular for the traditional cottage industries. This is due to the fact that East Coast Malaysia is known to be the cradle of Malay culture, strong religious belief, and commitment to the preservation of their customs, traditions and craft skills over time. The economies of the states are based on agriculture with rice, rubber, tobacco and fruits being main cash crops. In additions, fishing, fish and livestock are also primarily significant.

\section{RESULTS AND FINDINGS}

The main focus of youth development programs and activities in the country are for those aged between 18 to 25 years. The reason East Coast Malaysia was chosen because of the food industries have become an important business where the unique and delight food with popular Malay dessert or sweet known as 'kuih' such as dodol, keropok, kuih apam balik, bahulu, kuih bakar, lempuk durian, tapai, wajik sirat indigenous to the area. Stalls selling those foods can be found along every road throughout Kota Bharu, Kuala Terengganu and Kuantan as well as other towns of the states. The results shown, the youths are still fond of eating the traditional Malay kuih but only a small portion of them have the skill to prepare the traditional kuih.

Socio demographic profiles of the youth in East Coast Malaysia are summarized in Table I.

TABLE I: DEMOGRAPHIC PROFILE OF RESPONDENTS

\begin{tabular}{lcc}
\hline \hline Characteristic & Respondents & Percentage \\
\hline States: & 3 & 25 \\
Kelantan & 5 & 42 \\
Terengganu & 4 & 33 \\
Pahang & & \\
Gender: & 5 & 42 \\
Male & 7 & 58 \\
Female & & \\
Age: & 4 & 33 \\
18-19 & 3 & 25 \\
$20-21$ & 2 & 17 \\
$22-23$ & 3 & 25 \\
$24-25$ & & \\
Education: & 5 & 42 \\
SPM & 2 & 16 \\
STPM & 3 & 25 \\
Diploma & 2 & 17 \\
Degree & & 50 \\
Family Income: & 6 & 33 \\
Father and Mother & 4 & 17 \\
Father & 2 & \\
Mother & & \\
\hline \hline
\end{tabular}

The majority of the respondents interviewed were from Terengganu. Although the number of youth in Kelantan and 
Pahang as stated in the Table $\mathrm{I}$ is not as higher as in Terengganu, this scenario does not mean that the youth is less in these two states. A small number of the youth chosen from Kelantan and Pahang were due to the lack of participant of the respondents. Because of time constraint and cost/energy, the youths from Terengganu were more accessible compared those from Kelantan and Pahang. Female respondents gave more commitment and keen to participate compared to male respondents. In terms of age, the greatest frequencies of the youths who participate were at the age of 18 and 19. Data of this article demonstrates that the lowest age of respondent is the age 22 and 23. In terms of the educational status, all of the youth passed their Sijil Pelajaran Malaysia (SPM). Majority of them completed their studies up to Degree level. Fifty percent incomes of the family respondents come from both of the parents. Only small percentages come from single income.

Table II shows the result from the observation on youth perspective towards traditional Malay kuih and has shows certain distinct characteristics.

TABLE II: OBSERVATION ON YOUTH PERSPECTIVE TOWARDS TRADITIONAL KUIH IN EAST COAST MALAYSIA

\begin{tabular}{|c|c|}
\hline Field Work & Characteristic \\
\hline \multicolumn{2}{|l|}{ Observation: } \\
\hline $1,2,3,4$ and & Degrees of awareness are diminishing: \\
\hline 5 & $\begin{array}{l}\text { Just buy without understanding the main ingredients of } \\
\text { the kuih. They prefer to buy kuih that are colorful and } \\
\text { attractive yet it is containing a lot of food colorings. }\end{array}$ \\
\hline \multirow[t]{3}{*}{$1,3,5$ and 6} & Buying pattern: \\
\hline & Skip from buying traditional Malay kuih and tend to buy \\
\hline & $\begin{array}{l}\text { Modern dessert to follow the current trend, even if it is } \\
\text { expensive. }\end{array}$ \\
\hline \multirow[t]{3}{*}{$2,3,4,5$ and 6} & Gender differences: \\
\hline & Majority female youth try to avoid sweet kuih (for them \\
\hline & $\begin{array}{l}\text { Malay kuih are too sweet) because they consent on their } \\
\text { diets. Listening to their statement, they scared to get fat } \\
\text { because the local desserts are sweet. }\end{array}$ \\
\hline \multirow[t]{2}{*}{$3,4,5$ and 6} & Knowledgeable: \\
\hline & $\begin{array}{l}\text { Most of the youth are not familiar with the name of the } \\
\text { traditional Malay kuih. Knowledge of the product and } \\
\text { ingredients as well. }\end{array}$ \\
\hline \multirow[t]{2}{*}{$1,2,3,4$ and 5} & Perceptions: \\
\hline & $\begin{array}{l}\text { During Ramadhan(fasting month in Muslim calendar) } \\
\text { youth tend to buy traditional Malay kuih but very basic } \\
\text { kuih such as "kuih tepung pelita" and "kuih cara". }\end{array}$ \\
\hline \multirow[t]{2}{*}{$2,3,4,5$ and 6} & Peers influence: \\
\hline & $\begin{array}{l}\text { When going out with friends, they don't buy/eat Malay } \\
\text { kuih, but with family sometimes they will accept } \\
\text { traditional Malay kuih. }\end{array}$ \\
\hline
\end{tabular}

Some of the most important discussions among the youths during the interviews evolved around the extent to which food habits were linked to past traditions or to the future and around ideas of how the culinary culture will sustain especially the traditional Malay kuih. The challenges are according to whether they eat something ordinary and familiar or something extraordinary or strange. This modern isolation from the traditional authentic cuisine sparked some concern among food lovers, as they feared that traditional dishes and the preparation would fall into forgetfulness lest they be kept alive by producers and youth alike. Hence, "past" and "traditional" to some extent did represent prime value references and such became central signifiers for contemporary cultural ideals of how the future ought to be [9].

These are the challenges of sustaining the traditional Malay kuih meanings, the rules according to which can structure meals, combine certain elements, and in a given combination replace certain elements with certain others. These rules also pertain to the time of the day a given type of kuih is served. From the interviews, it was clear that for a good number of traditional Malay kuih products, youth were demanding alternatives to the products and brands offered by the large-scale producers so dominant in the food market. The themes are summarizes in Table III.

TABLE III: THE THEMES

\begin{tabular}{|c|c|}
\hline Themes & Categories \\
\hline Family & $\begin{array}{l}\text { Multiply of commitment } \\
\text { Practices at home } \\
\text { Bought kuih from food stall } \\
\text { Influences by relatives } \\
\text { Eating habits } \\
\text { Background }\end{array}$ \\
\hline Value & $\begin{array}{l}\text { Personality } \\
\text { Environments } \\
\text { Food beliefs } \\
\text { Behavior } \\
\text { Attitudes } \\
\text { Social transformation } \\
\text { Modern generation } \\
\text { Self-disciplined } \\
\text { Respectful }\end{array}$ \\
\hline Knowledge & $\begin{array}{l}\text { Names and types of kuih } \\
\text { Ingredients used } \\
\text { Method of preparation } \\
\text { Cooking technique } \\
\text { Molding/packaging technique } \\
\text { Appearance } \\
\text { After taste } \\
\text { Experience }\end{array}$ \\
\hline Motivation & $\begin{array}{l}\text { Encouragement } \\
\text { Passionate } \\
\text { Inspiration } \\
\text { Urge } \\
\text { Interest }\end{array}$ \\
\hline Way of life & $\begin{array}{l}\text { Time and convenience } \\
\text { Meal patterns } \\
\text { Dieting } \\
\text { Availability } \\
\text { Routine }\end{array}$ \\
\hline Pecuniary & $\begin{array}{l}\text { Double income } \\
\text { Cost } \\
\text { Price } \\
\text { Charge }\end{array}$ \\
\hline
\end{tabular}

\section{A. Family}

The family was a major influence on youth eating behavior. Several studies suggested that patterns may differ by family structure. The family mediates youth dietary pattern in two distinct ways: the family as a provider of food and the family influences food attitudes, preferences, and values that affect lifetime eating habit of the youth. Previously, [10] found that families with a non-biological mother (a step, adoptive, or foster mother) spend less on food than other two-parent families. It shows that biological family will spend more on food. Data analysis of this study confirmed that consuming certain types of traditional kuih is a practice that is embedded 
in Malays. In families, children are taught the importance and effects of certain foods as they grow up. This strongly influences their later acceptance of traditional kuih, especially culturally based food. As proven in previous literature, traditional food knowledge usually is passed on by the older to younger generations. However, as they transition toward greater independence and autonomy, food habit of youth reflected the changing role of parental influence on food choices especially on traditional kuih. The increase in dining out and buying take away food that occurs during youth is related to the decline in knowledge on the food and also on the traditional kuih quality.

Families of the twentieth century have experienced critical changes. Increasing rates of marital instability and unwed parenthood have reshaped family structures. Changing work patterns that moved an increasing proportion of mothers with young children into the formal work force have shifted role behavior within the household. Greater geographic mobility and the restructuring of the economic sector have rewoven the social fabric of local places. Thus, at the dawn of the twenty-first century families across the east Cost Malaysia look and function differently than did the families of their parents' and grandparents' generations.

Much attention has been focused on the implications such changes have for family well-being and youth development. While most scholars hesitate to label the family an endangered institution, there is widespread agreement that the challenges now faced by families are daunting, Evidence is mounting that the fragmented structure and hectic pace of modern family life strain even the capacity of middle-class families to effectively nurture children and other dependent family members such as the elderly [11].

For the period of the interviews most of the respondents do not so keen of traditional Malay kuih because they do not have very supportive parents who can play part in introducing the traditional kuih and encouraged them in making the kuih. In Farah (20 years old) situation were different, because she came from family who have a business in traditional food including traditional Malay kuih. She started helping her mother preparing traditional Malay kuih since she was 8 years old. She was surrounded by this environment and culture, circuitously she acknowledge and aware about traditional kuih. Research has shown that events during childhood often have lasting effect and bearing on the development and experiences in later life. Those early events either constrained or brought out the potential of later changes in a person. Therefore, it seems reasonable to mention that youth especially female childhood experiences may provide some of the antecedents that shape their knowledge in preparing traditional Malay kuih. Most of the youth who knows traditional Malay kuih also reported bonding more with their parents especially from their mothers and grandmothers.

\section{B. Values}

Values are the pervasive foundation that underlies youth preferences for traditional Malay kuih. In this article, values consist of constructs such as ethnic cultural background, food belief, knowledge and oral traditional from their family members or relative. All of these constructs are important determinants in consuming traditional food. The Malay society traditional kuih practices are mostly created based on their cultural beliefs and customs, which have been inherited from generation to generation and can be sustained. Base on interview with Fatihah she bring up: play

“....from my opinions, we still can sustain the traditional Malay kuih even though I have no ideas with this kuih. But I believe there is someone out there who is still caring on our traditional food including kuih. Maybe in terms of quality of the food it will be decreased and same goes to number of the people who consume traditional kuih also will be decreased but I am confident that we still can manage to preserve it......"

Values are belief systems that certain society is committed to and it's usually are handed down from one generation to the next. It plays a role in determining individual behavior by creating frameworks of acceptable behavior that guide individual of the society actions [12], [13]. Apparently, these values can be used to explain patterns of behavior in consumer studies, particularly in food habit studies [14]-[17].

Culture and cultural values are believed to affect all aspects of food behavior and are the foundations that motivate food choices and consumption. This statement is supported by [12] and [18] who argue that food, eating and nutrition are strongly shaped by custom and culture. According to [19], there are cultural value differences among consumers when it comes to issues such as healthy eating, sleeping, exercise and taking supplements or vitamins. Cultural attitudes and values also vary with regard to the perceived seriousness of various diseases [19], [20].

The cultural values influenced knowledge; this is because culture is acquired and conveyed formally or informally by verbal instruction, non-verbal cues or personal demonstration [21]. Food ideology is a body of belief relating to food and its consumption in a given culture or ethnic group [12]. Culture is a learned system of categories, rules and plans for how people live their life that form a complete design for living [13], [21]. While observed the culture it is not an accidental collection of customs or habits practiced randomly by consumers: it normally passes from one generation to the next [13].

Oral traditional and food beliefs are also important factors that influence traditional food consumption. Oral traditional inherited from previous generations influence traditional food consumption by virtue of being an integral part of the medium for transferring or learning culture. According to [22], some aspects of culture, customs and traditions are passed on verbally, even though written records of cultures may exist. Oral tradition is still one of the most preferred and trusted sources of knowledge, because the tradition itself is oral and performed repeatedly [22]. Oral tradition is valuable source of learning about one's own culture, and it helps develop cultures values [23]. Although the term is not formally used, traditional kuih are part of the traditional culture of Malay. Knowledge of traditional kuih is often passed on verbally from generation to generation.

Personal values are more useful than attitudes for understanding consumer motives and buying behaviour[24]. Personal values are determined by cultural values; however, 
they are not the same thing. Cultural values differ from personal values because:

[.....] personal values are referred to as the beliefs of individuals in a culture, while cultural values refer to normative beliefs which individuals have about how they are expected to behave by their culture [25] p. 49.

Insofar as culture influences value formation, it is ultimately the youth as consumer who decides whether to follow, adapt or even reject culturally based values.

Malaysia has experienced rapid structural changes and social transformation [26], which have created a modern generation quite different from previous generations. This social transformation affects the core values of consumers. According to [25], although consumers may have few culturally based values, they acquire hundreds of personal values throughout their life. Changes in lifestyle modify value systems. Individuals inherit cultural values from their ancestors and continue to acquire values throughout their lives. Cultural backgrounds may lead to personal value dimensions, which, in turn, confirm expectations. Variations in personal, societal and cultural experiences not only generate differences between individual value systems but also generate differences in the stability of value systems [27].

Instrumental values are basic conviction that a specific mode of conduct is preferable to an opposite or converse mode of existence [27]. Instrumental values are the means, ways, methods, instruments, tools or intermediaries to achieve end goals. The instrumental value of compassion consists of self-control (i.e. restrained, self-disciplined) and obedience (i.e. dutiful, respectful). These are each influenced by cultural values. The instrumental value of self-control consists of the elements of restraint and self-discipline, which are related to the accountability of Malays as a Muslim. It might also mean following and respecting culture custom and family tradition.

\section{Knowledge}

Knowledge plays an important role in influencing traditional kuih preferences; therefore, in this article, it comprises current knowledge concerning traditional Malay $k u i h$ and the capacity to ascertain the necessary information to make an informed decision regarding food choice. As knowledge is affected by cultural values, it incorporates the traditional knowledge that has been inherited from earlier generations and conveyed through informal learning and formal knowledge acquisition from the mass media and other sources. Therefore, it is clear that knowledge pertaining on traditional Malay kuih can be effectively circulated by good communication strategies.

One of the crucial factors in the consumer acceptance of, and decision ' making about, food is 'knowledge [28], [29], [30], [31]. Changes are dietary attitudes and habits have been promoted by an adequate knowledge of diet-health relationships [28]. Throughout interviewing, eight (67\%) of the respondent did not have a good knowledge on traditional Malay kuih. According to one of them:

“....my mom just buys the traditional Malay kuih and asks me to eat. Without knowing the name of the kuih I just eat, she never explain to me about the kuih and I am not so sure whether she knows or not about the kuih maybe because I never ask...." (Haikal, 19)

Another $33 \%$ or four of the respondent were familiar with traditional Malay kuih. In general, if the families are knowledgeable towards traditional Malay kuih then the children will get an idea on the foods. This knowledge developed in the early childhood and is acquired throughout life and is likely to be reinforced by experience. Some knowledge may be lost, however, some early food experiences can last a lifetime. For example, oral tradition is one of the important sources for acquiring knowledge concerning traditional food in general and kuih to be more specific for Malay. This is because oral tradition is a valuable source of learning about, and understanding of, one's own ethnic culture. Youth can potentially access several sources of information from their environment.

\section{Motivation}

Youth decide to turn out to be engaged in public life when they have the motivation, opportunity, and ability to do so. But based on the results it proved that youth shown lack of interest and ability to become involved in sustaining the traditional Malay kuih, due to lack of information about specific knowledge and works towards traditional kuih. Youth today seems did not have basic skills especially in preparing the traditional Malay kuih compared to past generations. The motivation comes from a number of foundations:

1) A sense of responsibility to do so.

2) The satisfaction comes from participating with others for a common purpose.

3) The identification of a problem that will affect them or those people that they care.

4) The belief that when they involve in any situation it will make a difference.

\section{E. Way of Life}

Obviously way of life contribute certain point in influencing eating habits among youth because of the greatest cross-cultural diversity even thought all of them came from the East Cost of Malaysia who is strong in Malay culture and traditional food especially kuih. Beside perceived time constraints and convenience strongly change youth in choosing their traditional kuih. Throughout interviews with respondent from middle income families, convenience was a major driving factor in determining the choices of 'kuih'. Based on previous study [32], agreed that way of life and other factors such as family demographics, cultural back-ground, beliefs and practice will influence youth to consume food. If they want to try and eat the traditional Malay kuih, they just buy at any bazaar or food stall. This is much easier compared to making it yourself. In another finding, youth discussed wanting to sleep longer in the morning instead of taking the time to eat or prepare breakfast, not wanting to wait in line, eating at fast food restaurants because the food is served quickly, and choosing foods at home that can be prepared quickly. One of the remarks from the respondent was:

"People at my age are so busy, we don't have time to prepare dessert and it is too difficult to make traditional 
Malay kuih and we should spend a lot of time in the kitchen, I don't think my Mom can do also because they are busy working".

Studies of youth have found that taste is considered the most important influence on dessert selection, followed by cost. Although fewer studied have been conducted with youth, it appears that youth are also price sensitive. They prefer not to buy the traditional kuih so the money they can use for other thing. Sometimes they skip from taking traditional kuih because they think it is not healthy. According to them the traditional kuih contains a lot of coconut milk and too sweet. Dieting is a common and widespread practice among youth, especially girls.

Although parents had little influence with what their youth eat outside the home, they can influence what foods or desserts are available and accessible in the home or nearby. The influence of peers and conformity to group norms are often considered hallmarks of youth. Peer exerts a major influence on overall youth behavior. They help to create the norms concerning behavior, particularly whether it is acceptable to the peer group. They spend a substantial amount of time together; eating is an important form of socialization. Because youth seek peer approval and social identity, it is assumed that peer influence and group conformity are important determinants in food acceptability and selection. During interview with Salina, she reveals:

“...during outing with friends, very seldom I order or buy Malay traditional kuih or dessert, or maybe not even ones. I prefer to order novel dessert to look more up to date....it quite weird if only I am the only one who ordered Malay kuih".

Youth will do anything to be accepted by their groups. They try to look modern and trendy. Throughout conducting field work, base on observation youth who are going out with family they still purchase local dessert or Malay kuih especially during Ramadhan (Fasting Month).

\section{F. Pecuniary}

Money has under gone many transformations since it settled in other cultures. It is not only a source and instrument of co modification and globalization; it is also subject to endless cultural reinterpretation and indigenization. This article has been an attempt to present additional material supporting that new appreciation of the social value of money and to show how money is personalized and symbolized in the lives of youth in East Coast community.

Money may have caused upheaval and destruction, but it also has become a source of happiness and security, an indispensable means of realizing reciprocity. According to Yusnita (respondent 11) money does not mean everything or sever relations, but it will bind people together. After one year married, she started selling traditional Malay kuih to help his husband to increase their incomes.

\section{CONCLUSION}

Globalization is a dynamic influence to the culture that gives impact and challenge to youth to sustain the traditional
Malay kuih. Everything changes so fast, and as a preventive measure in order to ensure the authenticity of Malay kuih. being well preserved, researcher need to collaborate with diverse groups and communities to educate them about the importance of protecting Malay heritage. Base on this study the factors that have already been identified and revealed are related to family, values, knowledge, motivation, and way of life and pecuniary/financial interact and affect youth perspective towards sustaining the traditional Malay kuih is needed for the development of effective interventions. Interventions addressing factors at the different levels of influence, which complement and build upon families, peers and each other, are needed to improve knowledge and behaviors and environment. Howe ever, as Malay youth they should have high esteem and honor towards Malay legacy and be proactive by engaged in any situation to protect their heritage. Self-motivation is important and has a significant to the psychological needs such as education and work. Accordingly, research guided by self-determination theory has focused on the social which is involved in self-motivation and psychological development of the youth. Therefore researcher strongly believe that everybody has to ensure that the youth being encourage enough to provide enough motivation and drive for them to have interest in learning about the Malay kuih and gain skill to prepare the kuih.

Nevertheless the challenge in helping youth to acknowledge traditional Malay kuih will require multifaceted and community-wide efforts. Thus, Malay food experts and professionals especially during preparing authentic Malay kuih, should play as a role model to influence youth behaviours to consume, to learn how to make traditional kuih through community outreach, advocacy work, and building partnership $\mathrm{s}$ with the food and restaurant industry, media groups, government programs and agencies, school and community organizations, policy makers, and youth groups. The challenges in sustaining the traditional Malay kuih not only weight on youth but whole community should participate and show interest in sustaining our heritage. Likewise, the Malay traditional kuih brought to these Malaysian flavours appear strongly. These kuih such as bahulu, dodol, tapai or lempok should be preserved before they are all gone. Within these food practices are the relationships that form parts of community and personal identity. These elements that remain invisible to most people until these is a person who star to see how these practices reflect the youth lives and those who helped shape them to appreciate their own food heritage.

As a conclusion, although the themes are reachable, this study faces some limitations that are inherent in the research method. One of the primary limitations of this study results from the lack of secondary data from similar studies in literature. Another limitation pertains to the sampling method. Owing to budget constraints information had to be collected only from capital city of these three states (Kelantan, Terengganu and Pahang) rather than the whole district in the East Coast Malaysia. As a consequence, findings had to be confined and interpreted within the characteristics of the themes. Hence, this present study highlights the need for further investigation and exploration on this topic in broader scope and different method. 


\section{NOTES}

Dodol - Made from glutinous rice flours, coconut milk and gula kabung/gula Melaka (brown sugar). It is made in various shape and flavor. Is a taffy-loke food delicacy popular in Malaysia and others neighborhood countries [33].

Lempok - It was stirring stuff, made from fresh durians thrown in a thick mass in a brass pot, flesh and stone, and stirred with bonding and sweetening ingredients plus coconut milk. The resulting paste bore the thread, unlike the genuine goo wrapped in upih (cellophane) now masquerading as 'durian cake' [34].

Kuih Bahulu - Known as traditional Malay cakes that are served as snack food amongst locals especially during Hari Raya celebrations. It soft and slightly dry texture, delicious to be eaten hot but can kept in airtight container. Comes in many shapes, but most popular are bahulu cermai (button) and bahulu ikan (fish). Traditionally to cook bahulu is by using bahulu mould and let it cook on charcoal fire [35].

Tapai - Made from glutinous rice or tapioca, ferment with ragi(is a natural-starter similar to sourdough) and sugar. It partially liquefied, sweet sour and mildly alcoholic, with a pleasant fragrant aroma [36].

\section{ACKNOWLEDGMENT}

This research is fully funded by Research Universiti Grant. The author would like to thank for the full support received from the Universiti Research Grant, Universiti Putra Malaysia. Thank you to the Department of Foodservice \& Management of the Faculty of Food Science and Technology for your assistance.

\section{REFERENCES}

[1] Z. Majid, "Malaysia heritage commissioner," The New Straits Times, pp. 24, May 112009.

[2] J. Jordana, "Traditional foods: Challenges facing the European food industry," Food Research International, vol. 33, pp. 147-152, 2000

[3] P. Skoglund and S. Eva, "Discourses of nature conservation and heritage management in the past, present and future: discussing heritage and sustainable development from Swedish experiences," European Journal of Archaeology, vol. 13, pp. 368, 2011.

[4] M. M. Omar, "Sustaining traditional food: consumers' perceptions on physical characteristics of Keropok Lekor or Fish snack," International Food Research Journal, vol. 18, pp. 7, 2011.

[5] Malaysia Statistic Department, "Population," Kuala Lumpur, Malaysia, 2010.

[6] S. H. Hassan, "Consumption of functional food model for Malay Muslims in Malaysia," Journal of Islamic Marketing, pp. 104-124, 2011.

[7] P. M. Homer and L. R. Kahle, "A structural equation test of the value-attitude-behavior hierarchy," Journal of Personality and Social Psychology, vol. 54, pp. 638-645, 1988.

[8] A. Emery and R. Tian. (2009). Opportunities vs. challenges: a cross-cultural approach to internet marketing. [Online]. Available: http://infosciencetoday.org

[9] J. S. BriaBrown, "Knowledge and organization: a social practice perspective," Organization Science, vol. 12, pp. 198-213, 2001.

[10] A. Case, I. Lin, and S. McLanahan, "How hungry is the selfish gene?" Economic Journal, vol. 110, pp. 781-804, 2000.

[11] E. David, A Sympathetic Understanding of the Child: Birth to Sixteen, 3rd ed. Allyn and Bacon 1994.

[12] P. Fieldhouse, Food and Nutrition: Customs and Culture, Chapman and Hall Ltd: London, 1995.

[13] G. M. Foster, Traditional Cultures: And the Impact of Technological Change, New York and Evanston: Harper and Row, 1962.

[14] J. B. Ford, M. S. L. Tour, and T. L. Henthome, "Perception of marital role in purchase decision processes: a cross-cultural study," J Acad Mark Sci, vol. 32, pp. 120-131, 1995.
[15] R. T. Green and D. L. Alden, "Functional equivalence in cross-cultural consumer behaviour: gift giving in Japan and the United States," Psychol Mark, vol. 5, pp. 155-168, 1988.

[16] M. Wallendorf and E. J. Arnould, "My favourite things: a cross-cultural inquiry into object attachment, possessiveness and social linkage," J Consum Res, vol. 14, no. 531, p. 47, March, 1988.

[17] J. Watson, S. Lysonski, T. Gillan, and L. Raymore, "Cultural values and important possessions: a cross-cultural analysis," Journal of Business Research, vol. 55, pp. 923-931, 2002.

[18] J. Sobal, "Cultural comparison research designs in food, eating and nutrition," Food Quality and Preference, vol. 9, pp. 385-392, 1988.

[19] L. M. Pachter, J. Sheehan, and M. M. Cloutier, "Factor and subscale structure of a parental health locus of control instrument (parental health beliefs scales) for use in a mainland United States Puerto Rican community," Social Science and Medicine, vol. 50 no. 5, pp. 715-721, 2000.

[20] M. Hilliam, "Functional foods: the western consumer viewpoint," Nutrition Reviews, vol. 54, pp. 189-194, 1996.

[21] A. Neal, P. Quester, and D. Hawkins Consumer Behaviour: Implications for Marketing Strategy, 4th ed., McGraw-Hill, Boston, MA, 2006

[22] E. J. Bakker, "Homer as an oral tradition," Oral Tradition, vol. 18, no. 1 , pp. 52-4, 2003.

[23] S. Chamarik, "Oral tradition in Thailand: a development perspective," presented at the Collection and Safeguarding the Oral Tradition, a Satellite Meeting of 65th IFLA Council and General Conference, Bangkok, August 16-19, 1999.

[24] M. Rokeach, "Part II. Religious values and social compassion," Review of Religious Research, vol. 11, no. 1, pp. 24-39, 1969.

[25] O. H. M. Yau, "Consumer behaviour in China: customer satisfaction and cultural values," Routlege, London, pp. 49, 1994.

[26] A. R. Embong, "Social transformation the state and the middle classes in post-independence Malaysia," in Cultural Contestations: Mediating Identities in a Changing Malaysian Society, Z. Ibrahim, (Ed.), ASEAN Academic Press, London, pp. 83-116, 1998

[27] M. Rokeach, "The nature of human values," Teachers College Record, vol. 77, pp. 298-303, 1975.

[28] S. Bhaskaran and F. Hardley, "Buyer beliefs, attitudes and behaviour: foods with therapeutic claims," Journal of Consumer Marketing, vol. 19, pp. 591-606, 2002.

[29] M. Hilliam, "Functional foods: the western consumer viewpoint," Nutrition Reviews, vol. 54, pp. 189-194, 1996.

[30] W. Verbeke, "Agriculture and the food industry in the information age," Oxford Journal: European Review of Agricultural Economics, vol. 32, pp. 347-368, 2005

[31] B. Wansink and J. Kim, "The marketing battle over genetically modified foods," American behavioural Scientist, vol. 44, pp. 1405-1417, 2001.

[32] S. Gable and A. Lutz, "Household, parents and child contribution to childhood obesity," Family Relations, vol. 49, pp. 293-300, 2000.

[33] T. Chuah, H. H. Nisah, S. T. Choong, N. Chin, and A. N. Sheikh, "Effect of temperature on viscosity of dodol (concoction)," Journal of Food Engineering, pp. 423-430, 2007.

[34] A. Goneng, Growing up in Trengganu, Singapore: Monsoon Books Pte Ltd, 2007.

[35] N. A. Wahid, "Heritage food tourism: Bahulu attracts?" in Proc. the 2nd National Symposium on Tourism Research, Universiti Sains Malaysia, Penang, Theories and Applications, Malaysia 18 July 2009 , Pulau Pinang: Social Transformation Platform, pp. 203-209. 14, 2009.

[36] Z. Merican and Y. Q. Lan, "Tapai Processing in Malaysia: A technology in transition," in Industrilization of Indigenous Fermented Foods. Second Edition, Revised and Expanded, K. H. Steinkraus, New York: Marcel Dekker, Inc, pp. 247-270, 2004

[37] S. Bhaskaran and F. Hardley, "Buyer beliefs, attitudes and behaviour: foods with therapeutic claims," Journal of Consumer Marketing, vol. 19, pp. 591-606, 2002.

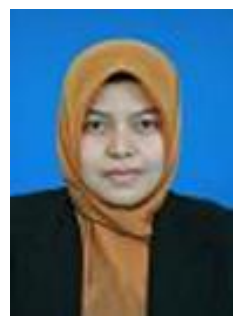

Humairah Hamzah was born in Pahang, located in the East Coast of Malaysia. She receives a bachelor degree of science (hons) food service management from Universiti Teknologi Mara (UiTM) in 1999, Master in Education (Technical) from Universiti Teknologi Malaysia (UTM) in 2002, and is currently pursuing her $\mathrm{PhD}$ (food service) with research at Universiti Putra Malaysia (UPM). Her interest is in traditional food, food culture and food heritage. She also serves as a lecturer at Politeknik Ibrahim Sultan (PIS) commencing from 2002 